\title{
Ambiente das mídias digitais: reflexões sobre comunicação e Educação
}

\author{
Belarmino Cesar Guimarães da Costa*
}

\section{Resumo:}

Antes de relatar as abordagens sobre mídia digital e fundamentos da educomunicação e da mídia-educação, que têm sido apresentados recentemente no Grupo de Pesquisa Comunicação e Educação (GP) da Sociedade Brasileira de Estudos Interdisciplinares da Comunicação (INTERCOM), o artigo formula juízos a respeito do processo de digitalização da informação e sua relação com experiências formativas tendo em conta tratar da relação entre técnica e estética num contexto de virtualização da realidade e da reconfiguração do estatuto da percepção. As modificações empreendidas pelo ambiente sociotécnico na desintermediação das práticas comunicativas e nas apreensões de inteligência, dentre outros aspectos, motivam reflexões sobre mobilidade, compartilhamento de informações e mudanças nas condições associadas à experiência humana.

Palavras-chave: Mídia. Educação - Inovações tecnológicas. Comunicação e educação.

* Doutor em Educação pela Universidade Estadual de Campinas (UNICAMP). Diretor e Professor da Faculdade de Comunicação da Universidade Metodista de Piracicaba (UNIMEP). Coordenador do Grupo de Pesquisa "Comunicação e Educação" da Sociedade Brasileira de Estudos Interdisciplinares da Comunicação (INTERCOM), e membro do GP Teoria Crítica e Educação, com sede na UNIMEP, UFSCar e UNESP/Araraquara. 


\section{Dimensões estéticas: tecnologia e inteligência}

No ensaio $A$ obra de arte na época de sua reprodutibilidade técnica Benjamin (1993) assinala que a sensorialidade humana é duplamente formada: pela condição interposta pela natureza e pelas mutações tecnológicas e do meio, as quais vão sofrendo transformações pela intervenção do trabalho e das condições criadas pelo homem para sua preservação. A formulação de Benjamin, afeta às modificações sensoriais e de representação, advindas com a fotografia, adquire contemporaneamente - com o processo de digitalização da informação e reconfiguração do estatuto da percepção - contornos mais complexos em termos de influir sobre a linguagem e inteligência humanas.

Os novos códigos simbólicos correspondentes à visibilidade mediada pelas tecnologias, em meio a um ambiente artificializado, sugerindo outras formas de representação da realidade, com os softwares de animação, imagens em 3D e holográficas, produzem modificações também nos processos tradicionais de comunicação e de formação da subjetividade já que a virtualização do real é acompanhada de transformações nas formas de convivência social, na maneira de organizar o conhecimento e de gerir politicamente o uso dos novos suportes midiáticos.

Os programas de animação - que produzem sensações simuladas, possibilitando interferências na apreensão do mundo e, com isto, agem sobre a memória, no campo do imaginário e nas condições de representação - são utilizados em circunstâncias de entretenimento e passam a ser incorporados igualmente pela produção jornalística. No âmbito da indústria cultural, resultam desse processo o surgimento de produtos híbridos, a maior incidência da linguagem publicitária e formas diluídas de identidade, incluindo a possibilidade de sigilo e projeções miméticas.

$\mathrm{Na}$ perspectiva ontológica e filogenética de que transformamos o ambiente sociotécnico e somos formados por ele e de que a racionalidade instrumental motriz da produção se localiza também nos meios de comunicação e nas interações que estabelecemos no convívio social, cabe identificar, como um exercício de diagnóstico do espírito desse momento histórico, os elementos afirmados como valores de modernidade. A aceleração, o consumo e a hipertrofia da imagem se tornam referências educativas, ou seja, mais do que as informações de que dispomos através dos 
sistemas digitais incorporamos a estética, a funcionalidade, a forma de operar dos suportes tecnológicos e de suas linguagens, as quais são extensivas ao corpo e à inteligência humanos. A educação significa, no contexto sugerido, estar ambientado a um mundo de frenéticas transformações, no qual toda mercadoria se torna rapidamente obsoleta e onde a representação do sujeito decorre das aparências construídas pela dimensão da falsa consciência.

A descrição de Benjamin que alude às formas de fixação da imagem, nas condições de reprodução alcançadas nas primeiras décadas do século XX - a propósito de conferir caráter material à percepção humana modificada pelas mediações tecnológicas - com o advento da digitalização da informação, adquire, portanto, contornos emblemáticos por estarmos, atualmente, diante de duas rupturas que promovem campos de "indiscernibilidade das fronteiras entre mentes e máquinas e os sistemas cognitivos híbridos"1 quais sejam: a da cibernética, atuando nas recombinações de linguagens, convergência de suportes e incorporação dos suportes tecnológicos na esfera do "mundo vivido"; e a da decifração do código genético com profundas modificações na ciência e na configuração corpórea do ser humano.

As máquinas de inteligência - num contexto de aceleração industrial e dos fluxos de informação e com a extensão sensório-intelectiva e imaginativa do corpo humano nas suas interfaces com a robótica, com as máquinas de simulação e de precisão - colocam, para a filosofia e a educação, o pensar sobre o que é o humano, sua condição e os processos de formação num ambiente artificializado pelo resultado do trabalho humano e de sua intervenção na natureza.

A formulação de Santos (2003) sobre a ambivalência entre tecnologia que atende às necessidades humanas, colocando-se, portanto, na condição de meio, e o fato de que hoje também se confunde com valores humanos (na perspectiva de finalidade) é esclarecedora:

Desde as revoluções científica e industrial que ocorreram na Europa, a tecnologia tem sido alçada de sua condição de meio para preencher necessidades humanas à de finalidade e objetivo da aspiração humana. Tal mudança também significou que a transformação tecnológica deixou de ser considerada e avaliada com base em valores humanos; ao contrário, a existência humana passou a ser 
considerada segundo o padrão da rápida mudança tecnológica. Já não se perguntava mais quais seriam os impactos sociais, culturais e ecológicos da introdução em larga escala de uma tecnologia específica, se ela era desejável ou imprópria. A tecnologia não precisava ser mais adaptada à sociedade e à natureza; passou-se a esperar que a sociedade e a natureza se adaptassem à tecnologia; e para essa adaptação impositiva e violenta, nenhum custo social e ecológico foi considerado excessivo. (SANTOS, 2003, p. 74-75).

Para os estudos que confluem teorias e identificação de objetos de interfaces entre educação e comunicação - que no Brasil são, expressivamente, apresentados nos Congressos anuais da Sociedade Brasileira de Estudos Interdisciplinares da Comunicação (INTERCOM) e da Associação Nacional de Pós-Graduação e Pesquisa em Educação (ANPEd) -, alguns eixos temáticos comportam abordagens que transcendem a interpretação dos fenômenos pela sua aparência imediata. Ou seja, sobre as interfaces entre tecnologia, ambiente e existência humana há dimensões que ultrapassam as condições objetivas de produção, circulação e acesso à informação no sentido de que, no processo de trocas simbólicas, incorporamos também o modo de operar e de existir da sociedade tecnológica. Aliada à conformação dos aparatos, sua presteza em atender a determinadas necessidades informacionais, e à lógica de seu funcionamento subjazem dimensões éticas e estéticas, as quais permeiam a construção de imaginários, do campo semântico da linguagem e do destino da vida humana.

A informatização das sociedades, como uma etapa recente dos processos comunicativos - gerenciada pelos setores estratégicos da produção industrial e científica, de inteligência militar e com ramificações articuladas com o mercado -, requer fundamentos da educação e da comunicação para interpretar determinadas tendências, como a da desmaterialização dos suportes técnicos, além do fato de ocorrer uma migração de mídias para o espectro digital e a simulação instaurada em ambientes de informação jornalística, até então refratários ao comprometimento da ideia de objetividade e diferenciação com a esfera do entretenimento. Estruturas multimidiáticas, linguagens hipertextuais, hardwares e softwares que permitem formas de inteligência artificial - dentre outros fenômenos contemporâneos 
associados à digitalização - espreitam análises que suscitam interpretações capazes de explicitar não apenas interfaces e processos, mas também modificações cognitivas e de percepção.

Quando a imaginação humana faz incursão sobre a existência de máquinas que dispõem de dispositivos de inteligência, ainda mais numa condição associada à desmaterialização do suporte e à hipervalorização de determinados setores, como da produção científica, da indústria da informação e do entretenimento, o que ocorre, muitas vezes, é a fetichização da técnica, como se fosse possível isolá-la de sua incorporação nos processos civilizatórios. Quando isso acontece, a tendência é espetacularizar o real, sobretudo pela superexcitação visual. Nas palavras de Debord (1997, p. 23, grifos do autor):

O sistema econômico fundado no isolamento é uma produção circular do isolamento. $\mathrm{O}$ isolamento fundamenta a técnica; reciprocamente, o processo técnico isola. Do automóvel à televisão, todos os bens selecionados pelo sistema espetacular são também suas armas para o reforço constante das condições de isolamento das "multidões solitárias". O espetáculo encontra sempre mais, e de modo mais concreto, suas próprias pressuposições.

A não neutralidade da tecnologia e o fato de termos de ir além da dimensão instrumental significam considerar necessária a "desocultação" do uso dos suportes, suas linguagens e necessidades incorporadas no processo educativo e comunicativo.

Giacóia Júnior (2007, p. 136) recupera de Heidegger o termo alemão Entbergen para interpretar que: "Já não se trata mais de esperar de um movimento sociopolítico a promoção do encontro entre a técnica e o homem moderno, mas justamente de ultrapassar a técnica enquanto alguma coisa de técnico, para pensá-la em sua essência e em sua verdade.” Mais ainda: a técnica - ultrapassando-se a condição de instrumento e de meio predispõe ao desvelamento do real. Contudo, mediante incursão pela análise cultural e ao perscrutar as dimensões antropológicas dos códigos e das formas de uso da tecnologia é que se descortina a distinção da técnica como meio ou finalidade dela, na perspectiva fetichizante e adstrita ao âmbito da semicultura ou na condição auxiliar de emancipação humana. Isso significa 
que há uma dimensão antropológica e simbólica que permeia o problema da técnica e sua forma de incorporação nas sociedades, cabendo à educação, à filosofia e à comunicação tomarem-na como objeto de esclarecimento.

Um dos problemas é interpretar a técnica na perspectiva autotélica, como se os suportes tivessem autonomia e predisposição vocativa, ainda mais no âmbito dos debates sobre máquinas de inteligência, produção coletiva do pensamento e suposição de que softwares e outros aplicativos atuam numa esfera que não comporta a intervenção humana. As máquinas não são autoprogramáveis e nem dispõem de mecanismos autônomos que articulam experiência e linguagem. $O$ fato de processar informação, dispor de agilidade temporal para realizar cálculos e processar animações e efeitos de virtualização não lhes confere autodomínio no campo simbólico. Entretanto, os suportes de mediação tecnológica, ainda mais envolvidos com os processos de produção, difusão e acesso à comunicação, interferem na maneira de articular os juízos e a percepção, tal como foi descrito, e vão constituindo, no ambiente societário, novas formas de recomposição dos arquétipos simbólicos. A tribalização moderna encontra nos games, na produção cinematográfica e para a televisão formas de representação do homem/máquina que constituem universos semânticos sobre o corpo, o valor atribuído à sociedade industrial e à maneira como ela organiza a produção e a vida que vão perfazendo o inconsciente coletivo e o imaginário das pessoas.

\section{Configurações da tecnologia e o campo semântico}

A nanotecnologia, os circuitos de condução energética, a convergência de suportes e o hibridismo das linguagens, o fato de vivermos num ambiente de aceleração e de virtualização da realidade, dentre outros aspectos associados à Modernidade, fazem com que tenhamos uma percepção naturalizada da tecnologia. Em boa parte, essa sensação decorre da "intangibilidade dos suportes" e o fato de o ambiente sociotécnico requerer determinadas habilidades sensoriais e de inteligência faz com que ocorra a predisposição para se mistificar a tecnologia e não perceber que, por mais híbridas e próximas que sejam suas estruturas do corpo e da mente humanos, elas não dispõem de subjetividade e memória involuntária, para utilizar uma expressão proustiana, da série Em busca do tempo perdido. 
Daí supor-se que, além do esclarecimento sobre o caráter instrumental e das dimensões éticas e políticas da tecnologia, o período da digitalização informacional, no âmbito dos estudos que estabelecem interfaces educação/ comunicação, requer outro tipo de enfrentamento: aquele que passa pelo campo semântico. Inúmeras expressões, cunhadas na época da centralidade das tecnologias impressas e eletrônicas, são insuficientes para designar os fenômenos associados à mediação da comunicação digital, tendo em conta as rupturas causadas na esfera da percepção e da inteligência, bem como da interação e do compartilhamento de informações em estruturas descentradas e em rede como na Internet.

Terminologias que recorrem às teorias da informação, do início do século XX, nomeadas, então, por termos da eletrônica, já não abarcam a complexidade dos processos comunicativos. Outras, ao se aventurarem em imaginar uma plena simbiose entre homem e máquina, como "hiperhumano", "inteligência artificial", "era pós-biológica" propendem a separar a condição humana daquela surgida com circuitos e estruturas inanimadas como se estas dispusessem de memória, linguagem e vontade autônomas.

Mesmo encontrando-se tênues as fronteiras entre as dimensões antropológicas e as artificialmente criadas pelas tecnologias, e por mais que haja mudanças nas configurações de mente, corpo e inteligência, a distinção entre homem e máquina ocorre, invariavelmente, na esfera da experiência. Ter experiência expressa - de alguma maneira - que o conhecimento decorre da ação do sujeito na realidade, na perspectiva de que ele empreende modificações no meio e é transformado por este, inclusive pelas mediações que cria com o trabalho e com o invento das tecnologias. Na condição de vivermos numa sociedade de virtualização do real, as mediações tecnológicas provocam rupturas de experiência na medida em que ressignificam as noções de tempo e de espacialidade; assim, num contexto de aceleração e de compartilhamento informacional, agem sobre a subjetividade, juízos estéticos e nas formas de construção simbólica.

Portanto, o fato de haver mudança na configuração das dimensões espaciais, das experimentações tidas hoje como sistemas de complementaridade da máquina em relação ao corpo humano (na arte, nos games, nas animações), cada vez mais assinala a ideia de vivenciarmos e interiorizarmos experiências que incidem sobre a subjetividade. A virada cibernética e da linguagem da informática constrói outros parâmetros para 
a vida humana. Modifica-se o meio que perfaz a construção do humano. Uma melhor compreensão da mente humana, traçada paralelamente aos estudos de inteligência artificial e dos experimentos na esfera do virtual, ajudará a identificar o que distingue o homem da máquina, o neurônio do chip, as tarefas cerebrais daquelas processadas como informação.

\section{Tecnologia: do trabalho para as formas de convivência}

Para a sequência da exposição, cabe rememorar as incorporações tecnológicas associadas à digitalização, as quais articulam processos complexos de inteligência e de interação do homem e da máquina; além de facultarem a ampliação da capacidade de produção, circulação e acesso de informação, também atuam decisivamente nas modificações da forma de percepção humana, da gestão política do conhecimento e do deslocamento e hierarquização dos produtos simbólicos. Nesse momento em que a indústria cultural ocupa o espectro digital e as produções simbólicas intercambiam em esfera sistêmica e global um fenômeno é importante identificar: o fato de a tecnologia ter sido incorporada para além do ambiente tradicional de trabalho, sendo que, no mundo das relações de convivência, a lógica da produção passou a atuar no ritmo acelerado, na racionalização do tempo livre e no fato de, rapidamente, tudo poder tornar-se obsoleto.

Eis um comentário de $\operatorname{Kehl}(2004$, p. 57) a propósito da relação entre trabalho e tempo livre, tendo como eixo a mediação televisiva e publicitária: "O binômio diversão/distração é a realização de um modo de ocupação do tempo livre que, sendo a continuidade da lógica do tempo do trabalho alienado, não solicita o trabalho do pensamento." A transcrição dessa passagem tem o propósito de incluir, rapidamente, a ideia de que a falsa consciência decorrente das condições de produção se encontra reproduzida nas estruturas miméticas produzidas pela indústria cultural. Na Dialética do esclarecimento consta a afirmação de que o industrialismo "coisifica as almas". Faz sentido o registro: "O preço da dominação não é meramente a alienação dos homens com relação aos objetos dominados; com a coisificação do espírito, as próprias relações dos homens foram enfeitiçadas, inclusive a relações de cada indivíduo consigo mesmo." (ADORNO; HORKHEIMER, 1985, p. 40). 
Retomando o enfoque sobre o suporte midiático digital, com suas estruturas de convergência e mobilidade, constata-se que as técnicas de reprodução se encontram numa etapa qualitativamente diferente daquela representada pela tipografia e pela massificação dos meios eletrônicos: a "coisificação do espírito" precisa ser identificada nos ambientes de virtualização da subjetividade e na imersão imaginária em mundos onde se embaralham realidade e ficcionalidade. Na etapa associada à imaterialidade e à transferência de informações que permitem recombinações, de softwares a produzirem imagens sem referentes, um mundo no qual a publicidade administra desejos e o jornalismo espetaculariza a realidade, resulta um estado de excitação sensorial em que o acúmulo de informações não resulta necessariamente em autoconsciência. É uma dimensão educativa localizar, no espectro da digitalização da informação, a forma como a racionalidade industrial processa os campos do simbólico e do imaginário.

Diferentemente dos processos tradicionais de comunicação (impressos e eletrônicos), o suporte digital encontra-se na base da produção científica, na robotização e automação industrial, dentre outros setores que aliam informática, produção e serviços. Sua estrutura e linguagem encontram-se atuando, simultaneamente, nos momentos de trabalho, de entretenimento e de gerenciamento de informação. Aceleração, mobilidade, rupturas espaço-temporais vão se acentuando com o processo de digitalização da informação e com a capacidade exponencial de troca de bens simbólicos desterritorializados e produzidos para navegarem em ambientes convergentes e de interação midiática. A informação digital codifica imagens e representações, incide sobre as apreensões estéticas e na inteligência, perfazendo uma etapa em que a tecnologia é um fator que identifica estágios civilizatórios e, com isso, estabelece parâmetros para ações governamentais, militares e de controle energético, sobre a informação genética, do que circula internacionalmente pelas agências de notícias, entre outros.

Pelo fato de o suporte e a linguagem digital percorrerem todos os espaços de relacionamento humano e de sua estrutura se ajustar a interesses de áreas estratégicas de gerenciamento da informação como capital conjuntamente com a ampliação dos fluxos de informação, condições de acesso remoto, irrestrito e baseado no compartilhamento - temos uma dimensão estética de fundo: a de que os processos de digitalização da 
informação, de convergência tecnológica e da interação com meios que operam no plano da percepção multissensorial incidem na experiência do sujeito. A mediação tecnológica, portanto, não é apenas um recurso de adaptação, mas também um vetor de alteração da cognição e da percepção.

Nas exposições de trabalhos e nas reflexões sobre as interfaces educação, tecnologia e comunicação que têm permeado as atividades do GP - Comunicação e Educação da INTERCOM, nos encontros recentes de Natal (RN - 2008), Santos (SP - 2007) e Brasília (DF - 2006) observa-se que as investigações sobre objetos, linguagens e fenômenos associados aos novos suportes midiáticos se deparam com a perspectiva de reconhecê-los como agentes formativos, pois influem na educação estética, nos gostos e na formulação de juízos. Contudo, também são relatadas experiências abordando a apropriação dos meios de comunicação no ambiente escolar, em projetos de inclusão, extensão universitária e de interpretação de suas linguagens, condições de uso social e político, mormente para expor fundamentos epistemológicos da educomunicação, da mídia-educação e dos estudos de mediação cultural.

Uma questão recorrente nesses encontros do GP Comunicação e Educação, sugerindo aprofundamento teórico e metodológico, diz respeito às rupturas empreendidas pelas tecnologias digitais nas noções de espaço e de temporalidade. Isso porque o fluxo descentrado, móvel e hipertextual, característico da configuração dos novos suportes, suas linguagens e manejo pelo usuário processam informação e mudanças nas condições de produção, difusão e acesso de conhecimento e, ainda mais, modificam habilidades do corpo e atuam, portanto, em alterações dos esquemas sensórios e de cognição numa perspectiva antropológica e demarcada pelo argumento de que memória, imaginação e linguagem constituem-se processos transformáveis pelo ambiente tecnológico; neles, a aceleração e a estrutura matemática da informação específicas da informática passam a compor o universo simbólico de representações da natureza, das máquinas e da vida humana.

Partindo-se de uma perspectiva de esclarecimento, os processos comunicativos devem ser compreendidos numa condição transcendente ao imediatamente informado: não se trata apenas de apropriação de conteúdos, mas também da estética subjacente às mensagens e às estruturas dos meios 
e da experiência resultantes da interação mediada pela tecnologia (expressão tomada de THOMPSON, 1998). No ambiente sociotécnico e cultural associado às interações no ciberespaço ocorrem relações comunicativas as quais cotejam a racionalidade instrumental do processo de produção.

A dinâmica do fluxo de informações, a disposição das formas de codificação de mensagens e as condições que interpenetram estrutura dos suportes e esquemas sensórios e intelectivos humanos facultam supor que nos recentes ambientes de informação digital apreendemos conteúdos e abstraímos a moral dominante e somos inseridos num contexto demarcado pelas imprecisões entre realidade e virtualidade. As estruturas comunicativas associadas à digitalização e sua apropriação pela cultura de massa tendem a tornar confusos os espaços da vida privada e aqueles concernentes à esfera pública. Desse processo, destaca-se a ambivalência por existirmos num meio de intensas relações e conexões e, ao mesmo tempo, estarmos diante do isolamento propiciado pela tecnologia. ${ }^{2}$ Formas de comunicações descentradas e impessoais coexistem com um universo de ativação constante do conhecimento, através da ampliação dos fluxos de informação e de sua atualização. $\mathrm{O}$ processo de percepção e de inteligência nesse ambiente de interação mediada pelas tecnologias se dá de forma articulada com a expansão da indústria cultural, da "absorção do simbólico pelo econômico" e da maneira como a "a ciência se torna força produtiva." (CHAUI, 2006, p. 64).

A formulação desses juízos decorre da interpretação de que as tecnologias resultam de necessidades humanas e operam na esfera da transformação do meio social e do ambiente e de que há forças econômicas e estruturais agindo no sentido de sua funcionalidade. Como resultado desse processo nas tecnologias se materializa o espírito da época responsável pelo seu surgimento e dos esquemas de poder existentes.

A propósito, pontua Marcuse (1982, p. 19):

Em face das particularidades totalitárias dessa sociedade, a noção tradicional de "neutralidade" da tecnologia não mais pode ser sustentada. A tecnologia não pode, como tal, ser isolada do uso que lhe é dado; a sociedade tecnológica é um sistema de dominação que já opera no conceito e na elaboração das técnicas. 
A incorporação da racionalidade do mundo industrial e a possibilidade de subversão da lógica de funcionamento das tecnologias, na perspectiva educativa e de mobilização político-social e na esfera estética, têm motivado o diálogo no GP Comunicação Educativa da INTERCOM sobre as potencialidades das novas tecnologias em reproduzir, de um lado, as condições de desigualdade estruturais do sistema industrial e capitalista; de outro, em função das condições de interação, desintermediação da produção e acesso, bem como do caráter multissensorial dos meios, de subverter as condições de poder e fazer com que os aparatos e os conteúdos por eles veiculados possam estar reorganizados numa perspectiva educativa. Isso significa - especialmente pelas experiências educomunicativas, estudos de recepção e estudos da linguagem - interpretar que os meios de comunicação não operam somente na dimensão instrumental, pois trabalham com o imaginário e com a formulação de juízos estéticos.

Antes, propriamente, de adentrar as questões responsáveis por mover os fundamentos teóricos, relatos de experiência e enfoques, os quais vêm sendo problematizados no GP Comunicação e Educação nos últimos anos, é necessário complementar que o ambiente da mídia digital coloca outras dimensões que mereceriam aprofundamento em outro momento, dentre elas: a da desmaterialização dos suportes; o fato de a transitoriedade das mensagens vir acompanhada pelo ambiente de hipertrofia da imagem e pelas técnicas de simulação do real; sobre a estetização da realidade em decorrência da montagem, corte e descontinuidade e de outros recursos estéticos de produção. ${ }^{3}$

\section{Comunicação e Educação: relato de viagem}

Nos Congressos da INTERCOM de Natal (2008), Santos (2007) e Brasília (2006), em meio a outros projetos de pesquisa sobre investigação dos meios de comunicação impressos e eletrônicos, também foi identificada a atenção com o ambiente sociotécnico associado à virtualização da realidade, à desintermediação das práticas comunicativas e ao fato de que as novas tecnologias propiciam mobilidade, compartilhamento de informações e mudanças de apreensão de sentidos e de experiências. Um ponto de partida é importante destacar: o fato de duplamente o GP vir potencializando a interface comunicação e educação na perspectiva de os suportes midiáticos 
atuarem na dimensão formativa; e na abordagem sobre a condição em que os suportes midiáticos são incorporados em atividades pedagógicas e didáticas no ambiente escolar. A percepção de que os meios não devem ser geridos exclusivamente na condição instrumental tem permeado os eixos temáticos e o GP tem reservado uma sessão, em seus encontros anuais, para aprofundar metodologias e fundamentos teóricos que contemplem as interfaces das áreas de comunicação e educação. $\mathrm{Na}$ tentativa de nomear os objetos e significá-los a partir do ordenamento criado pelas novas tecnologias, há um embate no campo semântico e novas expressões vão sendo delineadas para cotejar a complexidade dos problemas surgidos em função das estruturas físicas dos componentes, da mudança no meio de convivência resultante da interação homem e sistemas que processam informações e com as próprias condições de memória, aprendizagem e representação.

A expressão "ecossistema comunicativo", por exemplo, ilustra as mediações sistemicamente organizadas e articuladas das mídias impressas, eletrônicas e, hoje, crescentemente afetas à formatação digital, com esferas que transcendem o espaço do ensino formal e permeiam a organização do trabalho, as situações de entretenimento e de circulação de informações. Nessa perspectiva, determinados enfoques abordam experiências de comunidades virtuais de aprendizagem ou de teletrabalho, indicativos de florescimento de formas coletivas, descentradas e incorporando novas dinâmicas ao processo de ensino. A ressignificação de tempo e de espaço, o embate sobre territorialidade e aldeamento do mundo, novas formas de socialização e de acesso a bens culturais motivam a exposição de pesquisas sobre dispositivos da informática e de outros suportes que dão outras bases para a produção de conhecimento e práticas pedagógicas.

Como argumentado, as transformações científicas, tecnológicas e dos processos de interação mediados pelas tecnologias afetam - com a digitalização da informação e construções simbólicas que circulam imaterialmente pela infovia e potencializam condições de compartilhamento e convergência em diferentes mídias - a percepção, a imaginação e a forma associada ao pensamento humano. Constituem-se de mudanças antropológicas as quais atuam no âmbito das habilidades sensitivas e de inteligência, daí ser importante direcionar o debate para a esfera da educação para além das fronteiras escolares por envolverem recortes no trabalho, nas formas de convivência e de produção, circulação e acesso de informação. 
Em função da incorporação dos suportes midiáticos, dos quais se pretende inventariar suas linguagens, novas formas de sociabilidade e estratégias educativas, o GP tem debatido aspectos relacionados às estruturas formais existentes nos ambientes escolares e, diante disso, deparase constantemente com experiências que buscam flexibilidade, interação entre os atores envolvidos com o processo de ensino e meios técnicos, bem como as pesquisas estimulam novas práticas que contemplem ações combinadas entre diferentes áreas do conhecimento. Experiências de Educação a Distância (EaD), evocando o papel do docente, as técnicas de uso e linguagem das Tecnologias de Informação e Comunicação (TICs), exploram aspectos relacionados a recursos, didáticas e as mediações dos aparatos no processo de simbolização e de mediação cultural. Novas habilidades aparecem, e alguns trabalhos apontam para isso, quando o processo de aprendizagem ocorre em ambiente de multimídia e marcado pela dialogicidade e pela disposição modificada das relações espaciais e de acesso à informação. Daí advém argumentos de que a interação mediada pelas tecnologias faculta a coautoria, o encantamento da educação e uma pedagogia ativa.

A propósito da inovação tecnológica e das habilidades requeridas em termos de apropriação docente das linguagens, dos efeitos estéticos e técnicos, cabe a seguinte observação de Hack (2008, p. 8):

O processo educacional docente é desafiado cotidianamente devido à introdução de mídias e multimídias na educação. Novas habilidades são requeridas do professor atualmente e uma experiência prática de produção audiovisual pode ser elucidativa, pois além de abrir a perspectiva de leituras multidisciplinares sobre a temática, trará a possibilidade de experimentar a roteirização e realização de peças educativas com alunos e professores voluntários. Por isso, é importante a projeção de outros estudos que aprofundem os fundamentos de uma produção audiovisual educativa que vá além da teleaula, ou seja, um produto que possa ser admirado por sua qualidade artística, como as obras cinematográficas. 
Diferentemente de algumas abordagens que tendem a se basear na tradição franfkurtiana e no fato de as tecnologias trazerem marcadas a lógica e a estrutura sistêmica das condições de seu surgimento, boa parte dos relatos busca desmistificar o caráter de manipulação a priori embutido na tecnologia, como se existisse uma correspondência inescapável entre o seu surgimento na sociedade industrial e capitalista e a redução de suas potencialidades transformadoras e educativas. Sociedade aprendente, ${ }^{4}$ sociedade da informação, sociedade do conhecimento, eis algumas expressões que acompanham o juízo de que as novas tecnologias facultam experiências estéticas e formativas transformadoras das condições tradicionais de ensino. Tais conceitos indicam a volatilidade das ideias que percorrem o fato de atribuir aos meios de comunicação lugar de polaridade para processos educativos, culturais e de mobilização social.

Com fundamento em Manuel Castells, Paul Virilio, Michel Maffesoli, Pierre Lévy, Umberto Eco, apenas para destacar alguns pensadores recorrentes, as pesquisas apresentadas no GP tendem a problematizar o ambiente do ciberespaço a partir do efeito das conexões em rede, da velocidade e deslocamentos de informações na perspectiva de apontar mudanças nas estruturas sociais, na reorganização da economia e da cultura pela influência das tecnologias. Sugerem, ainda, alterações no plano da inteligência mediante um contexto sociotécnico em que o trabalho e a comunicação se processam mediados pelos diferentes dispositivos digitais, eletrônicos e impressos.

Em função desse papel estratégico das tecnologias na mudança do ambiente natural e histórico, e que traz mutações nas habilidades sensitivas e intelectivas, afloram também, no GP, a importância de a instituição escolar inserir disciplinas, metodologias de análise e de comparação das características dos suportes midiáticos em termos de estrutura, linguagem e capacidade de armazenar, difundir e compartilhar informações. O argumento é o de que os alunos necessitam desenvolver a capacidade não apenas de manuseio, mas de decifração dos códigos e do lugar estratégico dos suportes em relação ao gerenciamento de conhecimento, às representações simbólicas e aos relacionamentos humanos. Interpretar as práticas comunicativas pela educação ou educar para as mídias têm sido um tema indicando a seguinte necessidade: a da inclusão nos currículos escolares de disciplinas com o papel de investigar a natureza e a influência 
das interações mediadas pela tecnologia, especialmente em suportes de apelo massivo, destacadamente a televisão. A perspectiva é a da implementação dos indicativos da Lei de Diretrizes e Bases da Educação Nacional (LDB) e dos Parâmetros Curriculares Nacionais do Ensino Médio (PCNs) que cotejam a necessidade de educar para o domínio da linguagem das tecnologias, seus códigos e integração com a sociedade.

Quando a questão da educação mediada pela tecnologia percorre os artigos e debates no GP, uma dimensão que aflora é a do trabalho docente numa variante que requer pensar em como se dá a sua formação numa sociedade na qual a racionalidade tecnológica pode minimizar a criatividade, a expressão e as condições materiais para o seu exercício. Dentre as perspectivas de abordagem sobressaem as pesquisas demarcando aspectos estéticos que tendem a valorizar as dimensões da teoria, da arte e das rupturas de percepção, como os estudos baseados na Teoria Crítica e de linguagem.

\section{Mídia e sociedade: dimensões formativas}

Desde os primeiros encontros, o GP Comunicação e Educação se depara com a exposição de metodologias, relato de experiências e hipóteses de pesquisas e reflexões que demarcam a influência do Núcleo de Comunicação e Educação da ECA/USP, por meio do Projeto Educom. Em diferentes regiões do país, ressoam trabalhos sobre "educomunicação", uma terminologia criada para demarcar as interfaces educação/comunicação, fundamentos metodológicos, técnicos e estéticos, cujo propósito é o de estimular projetos e práticas de educação para mídia num sentido que lida tanto com a interpretação das linguagens quanto das ações formativas com o uso dos meios. Em particular, com vista a potencializar experiências com segmentos sociais excluídos do acesso e produção de mensagens simbólicas, já que o sistema de comunicação se encontra cindido pelo monopólio e pelo gerenciamento desigual entre as diferentes classes sociais.

As experiências de educomunicação têm encontrado em meios tradicionais, como o rádio e a televisão, alternativas para uma prática educativa de resistência que supõe tomada de consciência do papel social, cultural e político da mídia, numa perspectiva comunitária e, ao mesmo tempo, de emancipação, a exemplo do projeto "Educom.rádio", 
desenvolvido na cidade de São Paulo pelo Núcleo de Comunicação da ECA/ USP, em parceria com a Prefeitura, sob a coordenação do prof. Ismar de Oliveira Soares.

Nas sessões de fundamentos teóricos sobre as interfaces entre educação e comunicação, além das perspectivas norteadas pelo conceito de educomunicação, o GP tem valorizado os debates a partir de pesquisas focadas nos trabalhos de mídia-educação que tendem a potencializar dimensões éticas e estéticas da educação para a cidadania. Na perspectiva de Fantin (2008, p. 5), a mídia-educação se refere à "possibilidade de educar para/sobre as mídias, com as mídias e através das mídias, a partir de uma abordagem crítica, instrumental e expressivo-produtiva." A intensidade do fluxo de informações, o ambiente midiático permeado pela exposição visual, as condições de aprendizagem no contexto das hipermídias, as questões sobre inserção digital e aspectos culturais permeados pela necessidade de práticas que sejam educativas e permitam outras formas de construção simbólica e de apropriação dos suportes comunicacionais, no seu conjunto, têm sido contribuições temáticas e de juízos estéticos e éticos advindos das pesquisas expostas recentemente no GP Comunicação e Educação.

Outra perspectiva que acompanha a trajetória dos estudos e pesquisas de comunicação, mormente na América Latina, passa pelas condições de recepção tendo em conta o fato de que cada agente do processo comunicativo reage, interpreta e decodifica as mensagens dos mass media a partir do conhecimento que cada um tem das fontes, da linguagem dos meios e do conhecimento sobre os fatos narrados. ${ }^{5}$ Sobre as tensões e regulações acerca do processo de interpretação de mensagens eis uma passagem do texto "Campo Comunicação/Educação: Mediador de Recepção":

A emissão (seja verbal ou não-verbal, seja pessoa ou midiática, seja presencial ou a distância, seja um conjunto de todas essas modalidades) resulta também de um processo que revela as práticas culturais do emissor. Há, porém, uma distinção, uma marca, que se destaca na emissão: além das características já mencionadas, ela carrega as posturas regulatórias. $\mathrm{Ou}$ seja: o receptor vê, ouve ou lê o que foi considerado "adequado" aos valores hegemônicos da sociedade e aos objetivos da empresa ou empresas que produzem. 
Essas posturas regulatórias são da própria natureza do produto emitido. O receptor "lê" o produto de acordo com suas práticas culturais, como dissemos, mas o produto "lido" já vem pleno, ou mais ou menos, de uma reinterpretação do que aí está já, revelando uma reinterpretação que tenha sido considerada também adequada. (BACCEGA, 2008, p. 2).

Citelli (2000) entende que as experiências educomunicativas pari passu permitem a aproximação com o cotidiano e as condições socioculturais dos receptores e sugere ser a linguagem um jogo permeado de contradições. Para ele, a recepção sempre evoca conflito e a não unilateralidade interpretativa. Trata-se de, apesar da estrutura economicamente centrada e politicamente administrada pelas corporações de mídia, reconhecer que os processos comunicativos interpelam campos de conflito que reúnem linguagens, experiências e dimensões culturais que não são unívocas e nem eliminam as diferentes dimensões formativas dos sujeitos receptores. Daí ser estratégico ações educativas que elucidem processos afetos ao poder simbólico da indústria cultural e a maneira como se dá a estetização da realidade, através de recursos de montagem, do uso de recursos de simulação e de produtos semiculturais que oferecem a ilusão de ilustração.

Ao tratar da relação entre formação e experiência, Fantin (2008, p. 2) formula o seguinte juízo:

Pensar a educação como ação em busca de significação implica perceber o papel da mediação na relação entre sujeito e cultura no sentido de ampliar o conhecimento de si, do outro e do mundo, possibilitando tal entendimento como interações e experiências que os sujeitos constroem participando dos sistemas simbólicos da cultura. Para além da informação e da imagem, a comunicação e suas tecnologias têm apresentado outros modos de inteligibilidade do mundo.

O fato de os suportes midiáticos sugerirem outras possibilidades de "inteligibilidade do mundo", numa orientação mais focada em interpretar as conjunturas estruturais da sociedade da informação e da comunicação, outra dimensão recorrente nas reflexões do GP passa pelas condições de 
produção, circulação e superexcitação da imagem. As pesquisas buscam enfocar as novas condições de representação, incluindo aquelas decorrentes das simulações e realidades que se associam à virtualidade, e tratam também do enfoque ambivalente sobre a estetização da realidade quando as imagens têm o propósito de provocar o choque e, paradoxalmente, com a repetição, a dessensibilização do sujeito. Em outras palavras, os embates teóricos transitam pela visibilidade plena que se alcança numa sociedade onde tudo ganha a esfera pública até a extensão que as tecnologias facultam ao campo visual, tendo como pressuposto o alargamento da experiência e o compartilhamento de mensagens.

\section{Considerações finais}

O processo de digitalização da informação - e as mutações que acarreta na esfera das percepções e da inteligibilidade que tendem a modificar o meio no qual o homem se forma - constitui desafios para projetos educomunicativos e de elaboração sobre os efeitos estéticos, técnicos e culturais da incidência de mediações que alteram substancialmente a forma de organização da sociedade, dos fluxos de informação e de compartilhamento de bens simbólicos. Diante dos limiares da esfera do entretenimento e da informação, das passagens tênues do real para o virtual, da indistinção entre o que é privado e transita na esfera pública, tornam-se estratégicos ensaios teóricos e práticas de educação para mídia.

Os projetos de educomunicação, de mídia-educação e as formulações teóricas sobre estética, técnica e mediações nos processos de recepção que temos a oportunidade de vivenciar no GP representam avanços sobre os fundamentos da interface comunicação e educação em termos de construção de metodologias e compreensão da linguagem e da incidência dos suportes midiáticas no contexto da sociedade global.

A mídia tem se constituído em espaços de aprendizagem e de poder simbólico e, de maneira contraditória, sugere estratégias de emancipação e de colonização. Na tensão, cabe politizar as novas tecnologias, como observa Santos (2003), e fazer um diagnóstico das mudanças que elas operam na maneira de ser do homem e da sociedade, de tal maneira que a decifração de suas linguagens e potencialidades no campo da percepção e da inteligência resultem em ações educativas e transformadoras. 


\section{Notas}

1 Expressão incorporada da Tese de Doutoramento de Guimarães (2009).

2 A propósito do argumento de que a tecnologia tem um componente de isolamento, recomendamos a leitura do artigo "Teoria Crítica e Novas Tecnologias da Educação”, de Crochík (2003).

3 Dimensões relacionadas à banalização estética presente na produção jornalística e em outros setores da indústria cultural, bem como do espetáculo associado à exploração visual e à racionalidade técnica, abordamos no livro Estética da violência, jornalismo e produção de sentidos, de Costa (2002).

4 Expressão de Assmann (2004). Com fundamento na filosofia da educação e no pensamento de Morin o livro Reencantar a educação: rumo à sociedade aprendente (ASSMANN, 2004) suscita reflexões sobre tecnologia, educação e sociedade da informação. A perspectiva de Assmann é a de que as tecnologias se tornam elementos constituintes da maneira de organizar a vida e as formas de aprendizagem e de conhecimento.

5 No Brasil, uma experiência de análise de recepção pode ser ilustrada com a pesquisa de Silva (1985) sobre o Jornal Nacional, da TV Globo.

\section{Referências}

ADORNO, Theodor W.; HORKHEIMER, Max. Dialética do esclarecimento: filosóficos. Rio de Janeiro: Jorge Zahar Editor, 1985.

ASSMANN, Hugo. Reencantar a educação: rumo à sociedade aprendente. 8. ed. Petrópolis: Vozes, 2004.

BACCEGA, Maria Aparecida. Campo comunicação/educação: mediador do processo de recepção. In: CONGRESSO BRASILEIRO DE CIÊNCIAS DA COMUNICAÇÃO - INTERCOM, 31., 2008, Natal, RN. Natal, 2008. Mimeografado.

BRASIL. Ministério da Educação. Secretaria de Educação Média e Tecnológica. Parâmetros curriculares nacionais para o ensino médio. Brasília, 1999. 
BRASIL. Ministério da Educação. Lei 9394/96 de 20 de dezembro de 1996. Lei de Diretrizes e Bases da Educação Nacional. Brasília, 1996.

BENJAMIN, Walter. A obra de arte na época de sua reprodutibilidade técnica. 6. ed. São Paulo: Brasiliense, 1993.

CHAUI, Marilena. Simulacro e poder: uma análise da mídia. São Paulo: Fundação Perseu Abramo, 2006.

CITELLI, Adilson. Comunicação e educação: a linguagem em movimento. São Paulo: Senac, 2000.

COSTA, Belarmino Cesar Guimarães da. Estética da violência, jornalismo e produção de sentidos. Campinas, Piracicaba: Autores Associados/Editora da UNIMEP: 2002.

CROCHÍK, José Leon. Teoria crítica e novas tecnologias da educação. In: PUCCI, Bruno; LASTÓRIA, Luiz Antônio Calmon; COSTA, Belarmino Cesar Guimarães da (Org.). Tecnologia, cultura e formação... ainda Auschwitr: São Paulo: Cortez Editora, 2003.

DEBORD, Guy. A sociedade do espetáculo. Rio de Janeiro: Contraponto, 1997.

FANTIN, Mônica. A mídia na formação escolar de crianças e jovens. In: CONGRESSO BRASILEIRO DE CIÊNCIAS DA COMUNICAÇÃO - INTERCOM, 31., 2008, Natal, RN. Natal, 2008. Mimeografado.

GIACÓIA JUNIOR, Oswaldo. Ética, técnica e educação. In: PUCCI, Bruno; GOERGEN, Pedro; FRANCO, Renato (Org.). Dialética negativa, estética e educação. Campinas: Editoria Alínea, 2007.

GUIMARÃES, André Satler. Carne e bits: reflexões sobre a indiscernibilidade das fronteiras entre mentes e máquinas e os sistemas cognitivos híbridos. 137f. Tese (Doutorado em Filosofia)- Departamento de Filosofia e Metodologia das Ciências. Universidade Federal de São Carlos, São Carlos, 2009.

HACK, Josias Ricardo. O vídeo na educação a distância: reflexões sobre a comunicação educativa sem fronteiras. In: CONGRESSO BRASILEIRO DE CIÊNCIAS DA COMUNICAÇÃO - INTERCOM, 31., 2008, Natal, RN. Natal, 2008. Mimeografado. 
KEHL, Maria Rita. O espetáculo como meio de subjetivação. In:

BUCCI, Eugênio; KEHL, Maria Rita. Videologias: ensaios sobre televisão. São Paulo: Boitempo, 2004.

MARCUSE, Hebert. A ideologia da sociedade industrial. 6. ed. Rio de Janeiro: Zahar, 1982.

SANTOS, Laymert Garcia dos. Limites e rupturas na esfera da informação. In: . Politizar as novas tecnologias: o impacto sóciotécnico da informação digital e genética. Rio de Janeiro: Editora 34, 2003.

SILVA, Carlos Eduardo Lins da. Muito além do jardim botânico: um estudo sobre a audiência do Jornal Nacional da Globo entre trabalhadores. 2. ed. São Paulo: Summus Editorial, 1985.

THOMPSON, John B. A midia e a modernidade: uma teoria social da mídia. Petrópolis: Vozes, 1998. 


\section{Digital media environment: reflections on communication and} Education

\begin{abstract}
:
Before reporting on the approaches to digital media and the basics of educommunication and media-education, which have been presented recently in the Communication and Education Research Group at Intercom, the article formulates judgments on the process of digitalization of information and its relation with educational experiences considering the relationship between technique and aesthetic in a context of virtual reality and the reconfiguration of the status of perception. The modifications undertaken by the sociotechnical environment in the disintermediation of communicative practices and in the apprehensions of intelligence, among other factors, motivate reflections about mobility, information sharing and changes in the conditions associated to the human experience.
\end{abstract}

Key words: Media. Education-Technological innovations. Communication and education.

\section{Ambiente de las Midias digitales: reflexiones sobre comunicación y Educación}

\section{Resumen:}

En el presente artículo, y antes de realizar el relato de las experiencias sobre los abordajes de la midia digital y los fundamentos de la "educomunicación" y de la midia-educación que fueron recientemente presentados en el Grupo de investigación Comunicación y Educación (GP) de Intercom, formulamos algunos juicios en relación al proceso de digitalización de la información y su relación entre técnica y estética en un contexto de virtualización de la realidad y de la configuración del estatuto de la percepción. Las modificaciones emprendidas por el ambiente sociotécnico en la des-intermediación de las prácticas comunicativas y en las aprehensiones de inteligencia, entre otros aspectos, producen reflexiones sobre movilidad, compartimiento de las informaciones y cambios en las condiciones asociadas a la experiencia humana.

Palabras-clave: Midia. Educación-Innovaciones tecnológicas. Comunicación y Educación. 


\section{Belarmino Cesar Guimarães da Costa}

Faculdade de Comunicação, Universidade Metodista de Piracicaba

Rodovia do Açúcar, Km. 156,

Piracicaba - SP

CEP: 13.400-911

E-mail:bcgcosta@unimep.br

Recebido em: 29/3/2009

Aprovado em: 30/5/2009 